This is the author's final, peer-reviewed manuscript as accepted for publication. The publisher-formatted version may be available through the publisher's web site or your institution's library.

\title{
Relationship maintenance behavior and adult attachment: an analysis of the actor-partner interdependence model
}

Rebekah D. Adams and Joyce A. Baptist

\section{How to cite this manuscript}

If you make reference to this version of the manuscript, use the following information:

Adams, R. D., \& Baptist, J. A. (2012). Relationship maintenance behavior and adult attachment: An analysis of the actor-partner interdependence model. Retrieved from http://krex.ksu.edu

\section{Published Version Information}

Citation: Adams, R. D., \& Baptist, J. A. (2012). Relationship maintenance behavior and adult attachment: An analysis of the actor-partner interdependence model. The American Journal of Family Therapy, 40(3), 230-244.

Copyright: Copyright @ Taylor \& Francis Group, LLC

Digital Object Identifier (DOI): doi: 10.1080/01926187.2011.605047

Publisher's Link: http://www.tandfonline.com/doi/abs/10.1080/01926187.2011.605047

This item was retrieved from the K-State Research Exchange (K-REx), the institutional repository of Kansas State University. K-REx is available at http://krex.ksu.edu 


\title{
RELATIONSHIP MAINTENANCE AND ATTACHMENT 1
}

\author{
Relationship Maintenance Behavior and Adult Attachment: An Analysis of the Actor-Partner \\ Interdependence Model \\ Rebekah D. Adams ${ }^{1}$ and Joyce A. Baptist ${ }^{1}$ \\ Kansas State University \\ Abstract
}

Associations between relationships maintenance behaviors (positivity, openness, assurances, and sharing tasks) and anxious and avoidant attachment were examined in 265 married couples. Using structural equation modeling to employ the actor-partner interdependence model, the use of positivity, assurances and sharing tasks were found to be negatively associated with anxious and avoidant attachment for both husbands and wives. Being open and self-disclosing in marriage was not strongly associated with attachment. Results indicated that the use of maintenance behaviors in marriages could have the potential to foster increased security in partners. Research and clinical implications are discussed.

Keywords: attachment, relationship maintenance behavior, marriage, dyadic analysis, SEM, APIM

Rebekah D. Adams, M.M.F.T., Graduate Student, and Joyce A. Baptist, Ph.D., Assistant Professor, School of Family Studies and Human Services, Kansas State University, equally contributed to this paper.

Correspondence concerning this article should be addressed to Joyce A. Baptist, FSHS, 302 Justin Hall, Kansas State University, Manhattan, Kansas 66502. Email: jbaptist@ksu.edu. Phone: 7855326891.

Much of the literature on adult attachment has focused on the implications of the trait properties of attachment for individual and relational well-being (Davila \& Cobb, 2004). The ability of individuals to accommodate new information by updating the state properties of attachment (Bowlby, 1969), is not well-studied especially in regards to the specific features within marital relationships that could influence attachment levels. It is said that individuals who experience their partners as a secure base experience an increase in their attachment security (Davila \& Kashy, 2009) that could lead to increased bonding and interdependence. This interdependent feature of marriage further provides a foundation to conceptualize how an individual's emotion, cognition or behavior affects the emotion, cognition or behavior of their partner (Kelly \& Thibaut, 1978). In order to fully understand marital relationships and to develop interventions that could help marriages thrive, it seems necessary then to understand couple behavior in its relational context. Such information can inform marital therapy and other marital enrichment programs.

Methodologically, relational interdependence suggests the need to examine mutuality between partners (Kenny, 1996). To extend the current literature, this study examined how the use of relationship maintenance behaviors known to enhance relationship resiliency (Canary \& Stafford, 1991) are associated with attachment insecurity. We examined these maintenance behaviors utilizing the Actor-Partner Interdependence Model (APIM) designed by Kashy and colleagues (e.g., Kashy \& Kenny, 2000) to test simultaneous and independent modeling of actor and partner effects of maintenance behaviors on subsequent attachment levels as illustrated in Figure 1. More specifically, we examined the association between couple's reported use of relationship maintenance behaviors in enduring marriages and their reported attachment levels.

\section{The Nature of Adult Attachment}

Bowlby's (1973) original theorizing of attachment describes working models as being able to accommodate and assimilate new information. Working models, a result of the infant-caregiver relationship, are developed out of the attachment figure's availability and proximity during various emotional experiences or circumstances. The way the attachment figure responds during these experiences has the power to change attachment beliefs and patterns (Collins \& Read, 1994). Adult attachment theorizes that romantic pair-bonds replace partners' parents in their role as the primary attachment figure in adulthood (Seluck, Zayas, \& Hazan, 2010), and as a result, a function of the relationship is to regulate a partner's felt security. Pair-bonds were found to assume the status of primary attachment figures in romantic relationships that were of at least two years (Fraley \& Davis, 1997). The romantic partners' availability then could prompt individuals to behave in ways that would restore security. This impact of romantic relationships was found in the transition to marriage where attachment security increased overtime for newlyweds (e.g., Crowell, Treboux, \& Waters, 2002; Davila, Karney, \& Bradbury, 1999). The preeminent change in attachment 
relationships from parental attachment to pair bonds is the degree of mutuality (Bowlby, 1969). In pair-bond relationships, partners mutually derive and provide security.

The dynamic nature of adult attachment has been conceptualized using the life stress model, socialcognitive and individual-difference models. The life stress model, originally proposed by Bowlby (1969), suggests that life events and circumstances that are emotionally significant can change attachment security as adaptation to the new conditions occurs. For example, negative life events, such as perceptions of loss associated with events, and moods were found to be associated with greater insecurity on a day-to-day basis (Davila \& Sargent, 2003). Their findings suggested that self-reported attachment security constantly fluctuated in response to negative life events. The life stress model, however, has only focused on negative events and has had mixed results.

The social-cognitive model postulated by Baldwin, Keelan, Fehr, Enns, \& Koh-Rangarajoo (1996) noted that change in attachment security is a result of changing states of minds. Thus, different levels of attachment will be reported at different points in time depending on what was activated in their minds. This model highlights the temporal, state-like features of attachment. For example, the recollection of life events that activate feelings of loss will activate insecure attachment, and feelings of satisfaction in a marriage can bring about relational security (Davila et al., 1999).

The individual- difference model focuses on pathological individual differences that predispose individuals who have vulnerable features such as parental divorce, to be more prone to changes in their attachment levels (Davila, Burge, \& Hammen, 1997). Such individuals are said to possess less stable attachment models that are more amenable to change. All three models suggest the transient nature of attachment that can be activated by the proximity of external stimuli (life stress and social-cognitive models) or by the distal disposition (individualdifferences model). Given these findings, it can be argued that relationship behaviors can have an effect on attachment levels of each partner. In the following section, we explore the relationship between positive relational behaviors and attachment security.

\section{The Role of Maintenance Behaviors in Attachment Security}

Relational maintenance behaviors are said to help sustain a relationship's status quo or stage of development, preventing relationship deterioration and repairing relationships (Dindia \& Canary, 1993). These can be performed either strategically, aimed at producing specific outcomes, or routinely, performed with no specific intentions although they serve maintenance functions (Dainton \& Stafford, 1993). The use of these behaviors by one partner is said to be perceived by the other partner as an indicator of relationship quality (Canary \& Stafford, 1992). Subsequently while the continued use of these behaviors substantially predict liking one's partner, commitment in relationships, and relationship satisfaction (e.g., Canary \& Stafford, 1992; Ramirez, 2008; Stafford, 2003; Weigel \& Ballard-Reisch, 2008), its absence can potential to lead to the de-escalation or termination of relationships (Guerrero, Eloy, \& Wabnik, 1993).

Studies examining relationship maintenance behaviors have identified numerous behaviors that contribute to the stability and longevity of relationships such as Positivity (being optimistic and hopeful about the relationship), Openness (desire to disclose information to one's partner), Assurances (statements made that imply commitment or that the relationship has a future), Social networks (use of common friendships to gain support and keep the relationship enjoyable), and Sharing tasks (sharing household duties and completing shared responsibilities) (Canary \& Stafford, 1991). Although these behaviors are said to be integral to the stability of adult romantic relationships, openness was found to negatively affect relationship satisfaction (e.g., Stafford, Dainton, \& Haas, 2000).

It is theorized that openness as a form of self-disclosure is not important to sustain relationships (Dainton, 2000). One theory explains this finding to be related to the observation that openness and self-disclosure are reported on paper only because they are idealized as the hallmark of successful relationships (Parks, 1982; Stafford, 2003). Openness is said to have the potential to be hurtful in a relationship, rather than function to maintain it. No firm empirical basis for unconditional openness has been shown to be necessary and helpful to the relationship. However, previous research on the conditions needed for disclosure to be beneficial include disclosure that is occurring in an ongoing relationship, disclosure that is done in small steps, reciprocated, take the receivers feelings and responses into account, relevant to the current topic of discussion, meant to improve the relationship, and both creates and occurs within a climate of trust and supportiveness (e.g., Johnson, 1972). Stafford (2003) further outlines the discrepancy in the research regarding openness. Research does not show empirically that openness is associated with positive relationship characteristics like the other maintenance behaviors. However, openness continues to be included as a maintenance behavior used by individuals.

Although studies examining the effect of relationship maintenance on relationship satisfaction and other important characteristics abound (Canary \& Stafford, 1992; Canary \& Stafford, 1994; Dainton, 2000; Dainton, Stafford, \& Canary, 1994; Simon \& Baxter, 1993; Yum \& Li, 2007), few studies have examined the relational (actor and partner) influence of relationship maintenance behaviors. Ramirez for instance (2008) found positive 
associations between an individual's use of assurances and positivity and their own and their partner's levels of commitment. Individual's use of openness was further found to be negatively associated with their own and their partner's level of personal and moral commitment to the relationship. Weigel and Ballard-Reisch (2008) who studied commitment, satisfaction and relational maintenance found satisfaction to be positively associated with both the individual's use and their partner's use of all five maintenance behaviors including openness. Levels of commitment were also associated with certain maintenance behaviors used by individual partners. The more committed the individual, the more he/she used these behaviors. The study also found that when one partner was highly committed, the other partner would share more of their social network. These two studies combined support the proposition that individuals who want to maintain their relationships not only engage in these behaviors, but do so in a reciprocal manner.

Given that interpersonal relationships and events can influence attachment security, and that maintenance behaviors are associated with relational characteristics such as commitment and satisfaction, we hypothesize that maintenance behaviors will be associated with levels of attachment security within the relationship. Although previous studies found attachment levels to influence the use of relationship maintenance behaviors in married and dating couples (e.g., Dainton, 2007), these studies did not employ methods of testing actor and partner effects. Furthermore, given that attachment has been found to have more state like features, it is likely that these relationship behaviors would in turn be associated with attachment levels whereby increased use of maintenance behaviors will be related to increased levels of attachment security.

This study focused on maintenance behaviors that only depend on the actions of members within the relationship - positivity, assurances, openness and sharing tasks. Social networks that depend on availability of family and friends were omitted. Based on current literature, we hypothesized that actors' reports of assurances, positivity and sharing tasks will be negatively associated with their own and their partners' reported levels of anxious and avoidant attachment. In addition, actors' reports of openness will be positively associated with their own and their partners' reported levels of anxious and avoidant attachment.

\section{Participants and Procedures}

\section{Method}

Participants were parents/guardians of students from four classes at a large public university in the Midwest. Students were given the option to invite their parents to participate in this study for extra class credit. Students who chose not to invite their parents were provided an alternative assignment for extra credit. This study was approved by the university's Institutional Review Board. Students were provided with a packet that contained an invitation to participate, a consent form, a copy of the survey instrument with instructions and a pre-stamped return envelope that they delivered to their parents/guardians. Participants were provided the option of completing a hard copy of the survey or the online version of the survey. A total of 513 parents/guardians returned completed surveys and 273 completed the online version of the survey.

Relationship length ranged from 12 months to 60 years, with most marriages averaging 20 years. To compile a sample of long term marriages and minimize the range of duration, only the couples that had been married at least 15 years were included $(\mathrm{n}=265)$. Of the 265 couples, the average length of marriage was 27.20 years $(S D=$ 5.04). The mean age of the participants was $52.03(S D=5.16)$ for men and $50.24(S D=4.72)$ for women. The majority of men $(n=233,87.9 \%)$ and women $(n=241,90.9 \%)$ identified as White/European, while about 7 men and 7 women identified as Black/African descent, 10 men and 8 women identified as Non-White Hispanic/Latino, 1 man and 3 women identified as Asian, 5 men and 2 women identified as American Indian/Alaskan Native, 4 men and 4 women as having two or more races, 2 men identified as Other and 3 men did not disclose their race.

\section{Measures}

Relationship maintenance behaviors. The Relationship Maintenance Strategies Measure (RMSM, Canary $\&$ Stafford, 1992) was used to assess maintenance behaviors in romantic relationships. The scale was used to measure positivity (10 items), openness (6 items), assurances (4 items), and sharing tasks (5 items). Sample items included: "I have encouraged my partner to disclose his/her thoughts and feelings to me" (openness), "I have tried to be romantic, fun, and interesting with him/her" (positivity), "I have done my fair share of the work that we had to do" (sharing tasks), and "I have implied that our relationship had a future" (assurances). Participants responded to the statements by indicating their behaviors in the relationship within the preceding 2 weeks using a 7-point Likert scale from 1 (Strongly disagree) to 7 (Strongly agree). Higher values indicated more use of each of these behaviors in the preceding two weeks. Reliability estimates averaged from 0.81 to 0.86 (for brief reviews, see Canary, Stafford, \& Semic, 2002). For this study, the Cronbach's coefficient alphas were: Openness $(\alpha=.89, .91)$, Positivity $(\alpha=.91, .92)$, Assurances $(\alpha=.78,82)$, and Sharing Tasks $(\alpha=.86, .91)$ for men and women respectively.

Attachment. The Experiences in Close Relationships-Revised scale (ECR-R, Fraley, Waller, \& Brennan, 2000) was used to measure the two dimensions that underlie adult attachment: avoidant attachment (18 items) and 
anxious attachment (18 items). The anxious attachment subscale measures fear of rejection and abandonment. Sample item being; "I worry about being alone." The avoidant attachment subscale measures discomfort with closeness in intimate relationships. An item example being; "I get uncomfortable when a romantic partner wants to be very close." Participants rated items using a 7-point Likert scale from 1 (Strongly disagree) to 7 (Strongly agree), according to how they generally experienced the relationship with their current partner. Higher values indicated higher levels of anxious and avoidant attachment. Internal reliability estimates of the ECR-R were found to be satisfactory and comparable to those of the original ECR items (Brennan, Clark, \& Shaver, 1998), the coefficient alphas are reported near or above .90 . The ECR-R test-retest correlations were reported to range from .93 to .95 (Fraley et al., 2000). For this study, the Cronbach's coefficient alphas were .93 for both the anxious and avoidant scales for men and .94 and .95 for anxious and avoidant attachment respectively for women.

Data Analysis

Preliminary analysis included an examination of sex differences using MANOVA and the examination of intercorrelations using Bivariate Pearson correlations. Descriptive statistics and correlations are presented in Table 1. For the main analysis, Structural Equation Modeling (SEM) was employed to estimate the actor and partner effects in Figure 1 using AMOS 19 (Arbuckle, 2010). The structural model included actor effects (estimating effects of each person's relationship maintenance behaviors (IV) on their own level of relational attachment (DV) and partner effects (estimating effects of each person's relational maintenance behaviors on their partner's level of relational attachment). There were no latent variables in the model and the model was fully identified, fitting the data perfectly with chi-square and degrees of freedom equal to zero. To control for nonindependence, the two scores for each maintenance behavior were allowed to correlate along with the error terms for husbands and wives attachment scores. Separate models were run for each maintenance behavior. Variables were not standardized before the analysis; therefore unstandardized estimates are reported in the model (Kenny, Kashy, Cook, 2006).

We examined the differences in strength between husbands' and wives' actor effects, by constraining actor effects for both husbands and wives to be equal after testing the model with unconstrained paths. This process was utilized for testing differences in husbands' and wives' partner effects as well.

\section{Preliminary analysis}

\section{Results}

MANOVA used to examine differences across sex for study variables indicated main effects for sex, Wilks' Lambda $=.965, F(6,523)=3.18, p=.005, \eta_{\mathrm{p}}{ }^{2}=.035$. The Univariate $F$-tests further indicated differences in only sharing tasks between husbands and wives, $F(1,528)=11.94, p=.001, \eta_{\mathrm{p}}{ }^{2}=.022$, with wives reporting more use of sharing tasks compared to husbands. The correlations as reported in Table 1 among partners' maintenance behaviors and their attachment confirm that the data are nonindependent. For all four maintenance behaviors examined, both husbands' and wives' maintenance behaviors were negatively related to their levels of avoidant attachment. Husbands' and wives' assurance, positivity and sharing tasks were negatively related to their levels of anxious attachment. Furthermore, increased used of assurance, openness and positivity by husbands were positively related to wives' use of the same behavior.

\section{Primary analysis}

Actor effects. None of the constrained actor paths had a $\chi^{2}$ significantly higher than the unconstrained paths for both avoidant and anxious attachment, indicating that husbands and wives were similar in the strengths of their actor effects. Thus, we could examine the pooled effects which are presented in Table 2 and 3 . Results for actor effects for maintenance behaviors and avoidant attachment were found for both husbands and wives for all four maintenance behaviors and are reported in Table 2. For husbands and wives, the use of assurances, positivity, openness and sharing tasks were negatively associated with their own levels of avoidant attachment. Similar actor effects were found for husbands and wives levels of anxious attachment for all of the maintenance behaviors except openness, as reported in Table 3.

Results for assurances, positivity, sharing tasks supported our hypotheses. The use of assurances, positivity and sharing tasks for these couples were negatively associated with their own levels of both avoidant and anxious attachment. However, results for openness did not support our hypothesis. Results indicated that individuals' use of openness was negatively associated with their own level of avoidant attachment. In addition, no actor effects were found for openness and anxious attachment.

Partner effects. None of the constrained models for both anxious and avoidant attachment indicated a better fit than the unconstrained model, indicating that husbands and wives were similar in the strengths of their partner effects. Thus, we could examine the pooled effects which are presented in Table 2 and 3.

Partner effects for avoidant attachment revealed significant negative associations with assurances and positivity for husbands and wives. A significant partner effect between husbands' use of sharing tasks and wives' level of avoidant was found as presented in Table 2. 
Partner effects for both husbands and wives were found for assurances indicating that the use of assurances by one partner was negatively associated with their partner's level of anxious attachment. Wives' use of positivity was negatively associated with their husbands' level of anxious attachment but husbands' use of positivity did not yield significant associations for their wives' anxious attachment. Partner effects for openness and avoidant attachment were not found. Partners who used openness were not likely to have partners who reported avoidant attachment levels. A partner effect for anxious attachment, however, was found with the use of openness. Significant partner effects were found for the use of shared tasks with both levels of attachment insecurity indicating that individuals using shared tasks were likely to have partners who reported lower levels of anxious and avoidant attachment.

Comparison of actor and partner effects. A chi-square difference test was also performed to test the differences between the strength of actor and partner effects for both anxious and avoidant attachment. None of the models worsened the fit indicating actor and partner effects are comparable. The chi-square results for differences between actor and partner effects for avoidant and anxious attachment are reported in Table 2 and Table 3 respectively.

\section{Discussion}

This study examined the associations between husbands' and wives' use of maintenance behaviors and levels of attachment insecurity using APIM. Maintenance behaviors namely, positivity, assurances and sharing tasks were found to be negatively associated with attachment insecurity for husbands and wives. The significant negative associations indicate that partners who use these behaviors reported lower levels of attachment insecurity and have partners that also reported lower levels of attachment insecurity. While research confirms that attachment levels impact areas of the relationship (e.g., Dainton, 2007), the use of dyadic data to analyze adult attachment as a relational phenomena furthers the research and makes an argument that there is a relational component to adult attachment given that partner effects were found.

Partner effects indicated that individuals reported more secure attachment when they had partners that reported using more assurances, sharing tasks, and positivity to maintain the relationship. The use of assurances informs members of the relationship that the relationship has a future (Canary \& Stafford, 1991). This could be interpreted as a form of availability and proximity on the part of the partner. Assurances used by one partner communicate the presence and accessibility of that partner to the other, potentially decreasing anxious and avoidant tendencies. This finding support the idea that anxiously attached partners tend to seek excessive proof that they are loved (Shaver, Schachner, \& Mikulincer, 2005). Furthermore, the use of assurances by one partner has the effect of drawing the other partner closer, which may account for the lower level of avoidant attachment.

Similar responses appear to be true for positivity and sharing tasks. Individuals who reported speaking fondly of the relationship and engaged in fun activities had partners who reported less anxious and avoidant attachment. Consequently, gestures that signal interest in the relationship might contribute to partners' sense of security. Similarly, making efforts to assume responsibilities for daily household tasks could be reassuring and increase partners' sense of security.

Openness reported by one partner did not have a significant positive or negative association with the other partner's levels of avoidant attachment. It is possible that in this sample of long-term marriages, being open with one another is an on-going process of the relationship that does not surprise the avoidant partner thus, is less likely to be associated with the partners' security.

However, individuals who reported using openness also reported lower levels of avoidant attachment. Because avoidant individuals tend to minimize their proximity seeking behaviors, and tend to rely on themselves for their own needs (Seluck et al., 2010), it makes sense that they would be less likely to self-disclose and share openly. Therefore those who engage in openness would also report lower levels of avoidant attachment. The same was not found for individuals reporting higher levels of anxious attachment. Self-disclosure with their spouses was not associated with individuals' own levels of reported anxious attachment. There appears to be a difference in how openness is associated with anxious and avoidant attachment as well as how it impacts the individual and their partner that requires further investigation.

Individuals' levels of anxious and avoidant attachment were negatively associated with the use of assurances. An individual engages in assurances when they want the relationship to continue. It is likely then, that the more an individual overtly expressed a desire for a future in the relationship, the less attachment insecurity would be reported. Similar findings among positivity and sharing tasks indicated the positive association between these maintenance behaviors and secure attachment. Overall, behaviors that promote optimism, shared responsibility and partnership were associated with higher levels of secure attachment.

Limitations and Future Research Directions 
The current study contributes to the study of a relational phenomenon that had been previously studied by utilizing samples of undergraduate students and individual level analyses (Canary \& Stafford, 1993 \& Dainton, 2003). This study observed how the use of behaviors is associated with attachment insecurity at one point in time. The findings indicate that there are relational characteristics associated with the attachment levels of each member of the dyad. Specifically, characteristics classified as being integral to the continuation of the relationship were found to be negatively associated with not only an individual's level of attachment insecurity, but their partner's as well. These findings provide useful information about the relational nature of attachment in ongoing adult romantic relationships. Even though the study does not provide causal effects, the findings provide a foundation point to start the investigation of positive behaviors in the relationship that lead to increased attachment security. Longitudinal studies that examine the impact of marital duration and couple behaviors across time on adult romantic attachment security could further elucidate the processes that influence the state properties of attachment. Given that negative events can lead to changes in adult attachment levels (Davila \& Sargent, 2003), and positive behaviors are associated adult attachment in romantic relationships, future studies that examine the potential interaction that positive and negative events have on attachment might further our understanding of adult attachment in romantic relationships.

Despite the new knowledge that this study offers, there are some limitations. First, the sample for this study lacked racial and ethnic diversity limiting its generalization to couples with more ethnic diversity. Second, selfreport measures such as the ones used in this study are vulnerable to biases inherent in self-report measurement and susceptible to social desirability. Individuals may report the use of more maintenance behaviors that are socially sanctioned as being important to enduring relationships.

\section{Clinical Implications}

This study has implications for clinical practice. The association between maintenance behaviors and attachment levels indicate that the use of maintenance behaviors might benefit couples' attachment levels. As such, couples that report high levels of insecure attachment might benefit from increasing the use of positivity, assurances and sharing tasks. Couples could be coached to use more praise, acknowledgment and gestures that indicate their interest in their partner and relationship. Actions that indicate their intention to remain in the relationship and desire for the relationship to continue can also be helpful. Encouraging the couple to share household responsibilities can be reassuring. These actions have the potential to not only benefit the individual's relationship well-being but their partner's. More research is needed before we can know the role of self-disclosure in therapy. This is a controlled environment where the therapist can be a lot more directive with the timing and delivery of self-disclosure. This study's findings indicate that using openness was not associated with the attachment level of the individual or their partner. Clinicians therefore should be selective in encouraging couples to self-disclose in their relationships.

\section{References}

Arbuckle, J. L. (2010). Amos (Version 7.0) [Computer Program]. Chicago: SPSS.

Baldwin M. W., Keelan, J. P. R., Fehr, B., Enns, V., \& Koh-Rangarajoo, E. (1996). Social-cognitive conceptualization of attachment working models: Availability and accessibility effects. Journal of Personality and Social Psychology, 71, $94-109$.

Bowlby, J. (1969), Attachment and loss, Vol. 1: Attachment. New York: Basic Books.

Bowlby, J. (1973). Attachment and loss, Vol. 2: Separation. New York: Basic Books.

Brennan, K. A., Clark, C. L., \& Shaver, P. R. (1998). Self-report measurement of adult attachment: An integrative overview. In J. A. Simpson, \& W. S. Rholes (Eds.), Attachment Theory and Close Relationships. (pp. 4676). New York, NY: Guilford Press.

Canary, D. J., \& Stafford, L. (1991). Maintenance strategies and romantic relationship type, gender and relational characteristics. Journal of Social and Personal Relationships, 8, 217-242.

Canary, D. J., \& Stafford, L. (1992). Relational maintenance strategies and equity in marriage. Communication Monographs, 59, 243-266.

Canary, D. J., \& Stafford, L. (1994). Maintaining relationships through strategic and routine interaction. In D. J. Canary \& L. Stafford (Eds.). Communication and Relational Maintenance. San Diego, CA: Academic Press.

Canary, D. J., Stafford, L., \& Semic, B. A. (2002). A panel study of the association between maintenance strategies and relational characteristic. Journal of Marriage and Family, 64, 395-406.

Collins, N. L., \& Read, S. J. (1994). Cognitive representations of attachment: The structure and function of working models. Advances in Personal Relationships, 5, 53-90.

Crowell, J. A., Treboux, D., \& Waters, E. (2002).Stability of attachment representations: The transition to marriage. Developmental Psychology, 38, 467-479. 
Dainton, M. (2000). Maintenance behaviors, expectations, satisfaction: Linking the comparison level to relational maintenance. Journal of Social and Personal Relationships, 17, 827-842.

Dainton, M. (2007). Attachment and marital maintenance. Communication Quarterly, 55, 283-298.

Dainton, M., \& Stafford, L. (1993). Routine maintenance behaviors: A comparison of relationship type, partner similarity and sex differences. Journal of Social and Personal Relationships, 10, 255-271.

Dainton, M., Stafford, L., \& Canary, D. J. (1994). Maintenance strategies and physical affection as predictors of love, liking, and satisfaction in marriage. Communication Reports, 7, 88-98.

Davila, J., \& Kashy, D. (2009). Secure base processes in couples: Daily associations between support experiences and attachment security. Journal of Family Psychology, 23, 76-88.

Davila, J., \& Sargent, E. (2003). The meaning of life (events) predicts changes in attachment security. Personality and Social Psychology Bulletin, 29, 1383-1395.

Davila, J., \& Cobb, R. J. (2004). Predictors of Change in Attachment Security during Adulthood. In W. S. Rholes \& J. A. Simpson (Eds.), Adult attachment: Theory, research, and clinical implications (pp. 133-156). New York: Guilford Press.

Davila, J., Burge, D., \& Hammen, C. (1997). Why does attachment style change? Journal of Personality and Social Psychology, 73, 826-838.

Davila, J., Karney, B. R., \& Bradbury, T. N. (1999). Attachment change processes in the early years of marriage. Journal of Personality and Social Psychology, 76, 783-802.

Dindia, K., \& Canary, D. J. (1993). Definitions and theoretical perspectives on relational maintenance. Journal of Social and Personal Relationships, 10, 163-173.

Fraley, C. R., \& Davis, K. E. (1997). Attachment formation and transfer in young adults' close friendships and romantic relationships. Personal Relationships, 4, 131-144.

Fraley, R. C., Waller, N. G., \& Brennan, K. A. (2000). An item response theory analysis of self-report measures of adult attachment. Journal of Personality and Social Psychology, 78, 350-365.

Guerrero, L. K., Eloy, S. V., \& Wabnik, A. I. (1993). Linking maintenance strategies to relationship development and disengagement: A reconceptualization. Journal of Social and Personal Relationships. Special Issue: Relational Maintenance, 10, 273-283.

Johnson, D. W. (1972). Reaching out: Interpersonal effectiveness and self-actualization. Englewood Cliffs, NJ: Prentice-Hall.

Kashy, D. A., \& Kenny, D. A. (2000). The analysis of data from dyads and groups. In H. Reis \& C. M. Judd (Eds.), Handbook of Research Methods in Social Psychology (pp. 451-477). New York: Cambridge University Press.

Kelley, H. H., \& Thibaut, J. W. (1978). Interpersonal relations: A theory of interdependence. New York: Wiley.

Kenny, D. A, Kashy, D. A., \& Cook, W. L. (2006). Dyadic Data Analysis. New York: Guilford Press.

Kenny, D. A. (1996). Models of non-independence in dyadic research. Journal of Social and Personal Relationships, 13, 279-294.

Parks, M.R. (1982). Ideology in interpersonal communication: Off the couch and into the world. In M. Burgoon (Ed.) Communication Yearbook 5 (pp. 79-107). New Brunswick, N.J.: Transaction Books.

Ramirez, A. (2008). An examination of the tripartite approach to commitment: An actor-partner interdependence model analysis of the effect of relational maintenance behavior. Journal of Social and Personal Relationships, 25, $943-965$.

Seluck, E., Zayas, V., \& Hazan, C. (2010). Beyond satisfaction: The role of attachment in marital functioning. Journal of Family Theory and Review, 2, 258-279.

Simon, E. P., \& Baxter, L. A. (1993). Attachment-style differences in relationship maintenance strategies. Western Journal of Communication, 57, 416-430.

Shaver, P. R., Schachner, D. A., \& Mikulincer, M. (2005). Attachment style, excessive reassurance seeking, relationship processes, and depression. Personality and Social Psychology Bulletin, 31, 343-359.

Stafford, L. (2003). Maintaining romantic relationships: Summary and analysis of one research program. In D. J. Canary \& M. Dainton (Eds.), Maintaining relationships through communication: Relational, contextual, and cultural variations (pp. 51-78). Mahwah, NJ: Erlbaum.

Stafford, L., Dainton, M., \& Haas, S. (2000). Measuring routine and strategic relationship maintenance: Scale revision, sex versus gender roles, and the prediction of relational characteristics. Communication Monographs, 67, 306-323.

Weigel, D. J., \& Ballard-Reisch, D. S. (2008). Relationship maintenance, satisfaction, and commitment in marriages: An actor-partner analysis. Journal of Family Communication, 8, 212 - 229. 
Yum, Y., \& Li, H. Z. (2007). Associations among attachment style, maintenance strategies, and relational quality across cultures. Journal of Intercultural Communication Research, 36, 71-89.

Figure 1. Path model representing actor and partner effects between relationship maintenance behaviors and attachment levels.

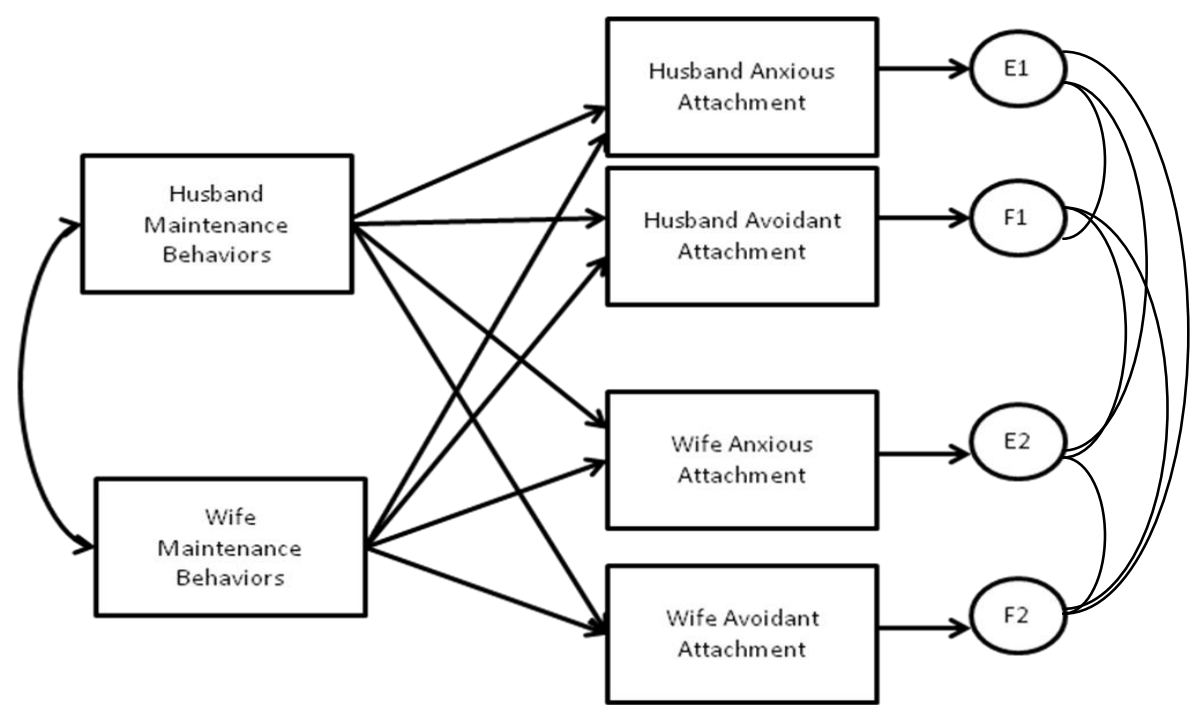

Table 2

Actor Partner Associations of Husbands' and Wives' Avoidant Attachment with the Use of Relationship Maintenance Behaviors.

\begin{tabular}{|c|c|c|c|c|c|}
\hline & $\begin{array}{c}\text { Husband } \\
\text { coefficients }\end{array}$ & $\begin{array}{c}\text { Wife } \\
\text { coefficients }\end{array}$ & $\begin{array}{l}\text { Differences } \\
\text { between } \\
\text { husbands and } \\
\text { wives }\left(x^{2}\right)\end{array}$ & $\begin{array}{c}\text { Pooled } \\
\text { husbands and } \\
\text { wives } \\
\text { coefficients }\end{array}$ & $\begin{array}{l}\text { Comparison of } \\
\text { Actor vs. Partner } \\
\text { effects }\left(x^{2}, 2 d f\right)\end{array}$ \\
\hline Assurances & & & & & 1.55 \\
\hline Actor & $-.12 * * *$ & $-.14 * * *$ & .70 & $-.13 * * *$ & \\
\hline Partner & $-.04 * *$ & $-.04 *$ & .08 & $-.04 * * *$ & \\
\hline Openness & & & & & 4.46 \\
\hline Actor & $-.04 * * *$ & $-.06 * * *$ & .86 & $-.05 * * *$ & \\
\hline Partner & -.01 & .01 & .48 & -.00 & \\
\hline Positivity & & & & & 2.93 \\
\hline Actor & $-.05 * * *$ & $-.06 * * *$ & 2.06 & $-.06 * * *$ & \\
\hline Partner & $-.02 * * *$ & $-.02 * *$ & .00 & $-.02 * * *$ & \\
\hline Tasks & & & & & 1.80 \\
\hline Actor & $-.07 * * *$ & $-.09 * * *$ & .94 & $-.08 * * *$ & \\
\hline Partner & -.02 & $-.03 *$ & .19 & $-.03 * *$ & \\
\hline
\end{tabular}

$* p<.05 . * * p<.01 . * * * p<.001$. 


\section{RELATIONSHIP MAINTENANCE AND ATTACHMENT 9}

Table 3

Actor Partner Associations of Husbands' and Wives' Anxious Attachment with the Use of Relationship Maintenance Behaviors.

\begin{tabular}{|c|c|c|c|c|c|}
\hline & $\begin{array}{c}\text { Husband } \\
\text { coefficients }\end{array}$ & Wife coefficients & $\begin{array}{c}\text { Differences } \\
\text { between } \\
\text { husbands and } \\
\text { wives }\left(x^{2}\right)\end{array}$ & $\begin{array}{c}\text { Pooled } \\
\text { husbands and } \\
\text { wives } \\
\text { coefficients }\end{array}$ & $\begin{array}{l}\text { Comparison of } \\
\text { Actor vs. Partner } \\
\text { effects }\left(x^{2}, 2 d f\right)\end{array}$ \\
\hline Assurances & & & & & 1.14 \\
\hline Actor & $-.06 * * *$ & $-.08 * * *$ & .40 & $-.07 * * *$ & \\
\hline Partner & $-.06 * * *$ & $-.04 *$ & 1.26 & $-.05 * * *$ & \\
\hline Openness & & & & & 1.15 \\
\hline Actor & -.01 & -.01 & .24 & -.01 & \\
\hline Partner & $-.02 *$ & .01 & 1.00 & $-.01 *$ & \\
\hline Positivity & & & & & 3.06 \\
\hline Actor & $-.04 * * *$ & $-.04 * * *$ & .13 & $-.04 * * *$ & \\
\hline Partner & $-.03 * * *$ & -.01 & 1.20 & $-.02 * * *$ & \\
\hline Tasks & & & & & 2.30 \\
\hline Actor & $-.04 * *$ & $-.07 * * *$ & 2.27 & $-.05 * * *$ & \\
\hline Partner & $-.04 *$ & -.02 & .37 & $-.03 * *$ & \\
\hline
\end{tabular}

$* p<.05 . * * p<.01 . * * * p<.001$. 